\title{
Developing a common language for transdisciplinary modelling teams using a generic conceptual framework
}

\author{
S. H. Hamilton ${ }^{a}, \underline{\text { W.S. Merritt }}{ }^{b}$, L. Carter $^{c}$, L. Lim-Camacho $^{c}$, U. Nidumolu ${ }^{\text {d }}$, M. Cosijn ${ }^{c}$, \\ R. Mishra ${ }^{\mathrm{e}}$, M. Dash ${ }^{\mathrm{f}}$, C. Roth $^{\mathrm{c}}$ \\ ${ }^{a}$ School of Science, Edith Cowan University, Joondalup, Western Australia, ${ }^{b}$ Fenner School of Environment \\ and Society, The Australian National University, Australian Capital Territory, ${ }^{c}$ CSIRO Land \& Water, \\ Brisbane, Queensland, ${ }^{d}$ CSIRO Land \& Water, Adelaide, South Australia, ${ }^{e}$ Centre for Development of \\ Human Initiatives (CDHI), Jalpaiguri, India, ${ }^{f}$ Shushilan, Khulna, Bangladesh \\ Email: wendy.merritt@anu.edu.au
}

\begin{abstract}
In developing countries, problems of poverty and the environment are inextricably intertwined, with any potential resolution requiring underlying political, social and economic causes to be addressed. An integrated research approach to examine such problems should not only involve a transdisciplinary team that covers the broad scope and perspective of relevant issues, but also ensure that interactions between different issues are deliberately explored. Differences in theories, methods, terminologies and research interests of team members, often hinders integration and leads to such complex projects being fragmented by disciplines. This paper describes a template for developing a conceptual framework for a project aimed at promoting socially inclusive and sustainable agricultural intensification in West Bengal (India) and southern Bangladesh. The project involves consideration of the various climate, market, environmental, social, political and health risks that threaten the livelihoods of these rural communities. The proposed template was designed to provide a common framework that the team can readily co-develop and thus overcome some of the challenges of working with transdisciplinary teams. This framework underpins the integrated modelling activities of the team.
\end{abstract}

In our conceptual framework template, processes are described in terms of a change to resources, the direct and indirect drivers of this change, and the direct and indirect impacts of the change. We selected terms that are unambiguous, yet broadly applicable and neutral, avoiding value-judgments. The use of more neutral terms will enable the framework to be used to represent both opportunities and challenges, as well as positive and negative directions of change. It will also help avoid imposing certain perceptions onto others - for example, what is viewed as a risk or disbenefit by some may be viewed as an opportunity or benefit by others. Therefore, the neutral language is more amenable to cross-cultural contexts and teams. A change in resources can include any increase or decrease in tangible and intangible assets, capabilities, capacities, or behaviours. Additional factors can be any factor that affects the rate of change - i.e. one that increases or reduces the magnitude of change or impact, or the capacity of the subject to avoid, cope with or adapt to the specified change. Examples of the use of the template are provided in this paper.

The template is modular in nature, so that diagrams can be readily combined to capture multiple system processes and complex pathways of influence. As multiple diagrams are combined, impacts from a change in one resource may become drivers for change in another resource. The template allows divergent ideas from the team to be mapped out and linked together in one common framework, facilitating a genuinely transdisciplinary process.

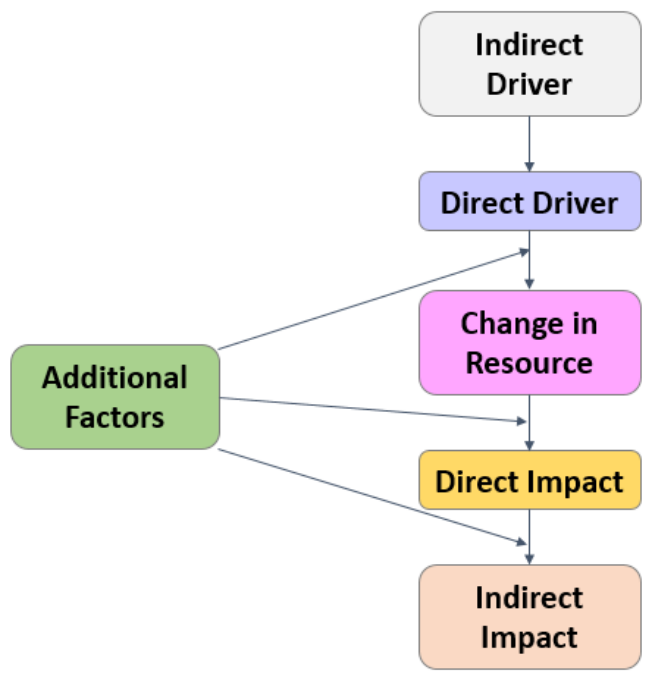

Figure 1. The proposed conceptual framework template for assessing system processes and changes

Keywords: Integrated modelling, integrated assessment frameworks, conceptual model 


\section{INTRODUCTION}

In developing countries, agriculture is typically the main source of income and livelihoods for the majority of rural people. Agricultural intensification, for example through high-yielding crop varieties, fertilisers, pesticides and irrigation, is increasing food production and has the potential to help alleviate poverty. However, the gains from agricultural intensification have not been equally distributed across communities, with more affluent groups in a much stronger position to reap its benefits. Marginal groups on the other hand, such as landless, smallholder and women farmers, and tribal minorities, have been left more exposed to adverse effects of agricultural intensification including environmental degradation and market risks. The people in these rural communities and their livelihoods depend on a large range of social, institutional, economic and environmental factors. Research in international development, and other nexus-type/cross-cutting fields, are increasingly faced with highly complex problems such as that of agricultural intensification described above. It is necessary for research that examines such complex problems to transcend traditional disciplinary and sectorial boundaries. This means not only involving a multidisciplinary team covering the broad scope of relevant issues, but also co-producing a holistic view of the network of issues (Tress et al. 2007; Bark et al. 2016).

There are challenges associated with most research for development projects - namely differences in theories, methods, terminologies and/or the research interests of team members - which can hinder integration and true transdisciplinarity. Transdisciplinary research is typically driven by multiple goals, which may be prioritised differently by team members according to their understanding, perspective, interest and values. These differences can stem from their respective discipline and sector, and also from their personal experiences and cultural background. Most disciplines have their own set of theories, assumptions, terminologies and research tools, which can result in alternative conceptual understandings of the system and technical differences in how they formulate, analyse and communicate concepts (Hamilton et al. 2015). In order to exploit and leverage the multiple expertise, these differences need to be moderated and pathways of integration and collaboration need to be facilitated (Klein 2008).

Integrative frameworks can be an effective pathway of integration and collaboration for transdisciplinary projects. Integrated assessment models, for example, provide a single platform to systematically organize and represent multiple issues and system components, and explore the linkages and feedbacks between them (Hamilton et al. 2015). There are a wide range of integrated modelling approaches available, suited to different applications and contexts, including system dynamics, coupled component models, Bayesian networks and agent-based models (Kelly et al. 2013). However, these integrated modelling approaches require at least some degree of quantification of relationships, and the problem to already be framed; in other words they are not suitable for the early scoping and problem formulation phases of a project. Conceptual models, on the other hand, can be useful for these earlier phases. Conceptual models provide a visual summary of one's understanding or hypotheses about the key elements, structure and workings of a system. They are also advocated as a platform to develop mutual understanding and learning amongst multiple disciplinary experts (Argent et al. 2016). There are a multitude of ways to develop and represent conceptual models, however, there seems to be a no clear guidance or framework for developing conceptual models for transdisciplinary problems that address the challenges mentioned above.

This paper describes a generic conceptual framework to elicit and communicate understanding about complex problems and systems, one that is suitable for transdisciplinary projects. The proposed template was designed

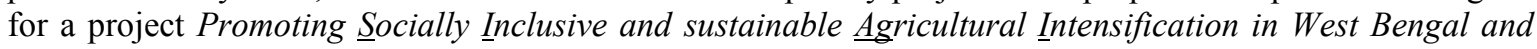
Bangladesh, referred to as "SIAGI". The project involves consideration of the various climate, market, environmental, social, political and health risks that impact the livelihoods of these rural communities. With over 40 project team members spanning a large range of expertise it was clear that SIAGI needed a common framework that all members could readily understand and co-develop. We apply the framework to capture early understanding of the key issues affecting the communities and how these issues were interlinked.

\section{BACKGROUND}

SIAGI is a four-year project funded by the Australian Centre for International Agriculture Research (ACIAR), and is still in its relatively early phases, entering its second year. The project aims to understand the drivers, impacts and risks of agricultural intensification in rural communities in West Bengal (India) and Bangladesh, and to identify opportunities and policy options that promote more socially inclusive and environmental sustainable intensification. SIAGI is examining a wide range of livelihood risks and opportunities associated with agricultural intensification including climate risks (e.g. rainfall variations, floods, cyclones), market risks (e.g. food price volatility), environmental risks (e.g. water quality, soil erosion, land degradation), social risks (e.g. social exclusion, increasing inequity), political risks (e.g. political unrest, changes in policies or institutions) and health risks (e.g. poor dietary diversity and quality). Four villages in two broad agro-ecological 
settings - the Eastern Gangetic Plains in West Bengal and the Coastal Zone in southern Bangladesh -serve as the main case studies for the project. Given the broad scope of the problem, SIAGI is adopting a wide suite of methods to acquire relevant information and data, including participatory community engagement processes, value chain analysis, policy analysis and institutional mapping, bio-economic modelling and integrated assessment modelling. One of the challenges within the project team has been ensuring these activities remain integrated, rather than dispersing into several somewhat related but disjointed activities. There have been substantial efforts through team planning, workshopping, organization and communication to ensure that the research activities combine, or at least feed into one another.

The project team includes over 40 people from 10 organisations (universities and other research institutions, non-government organisations [NGOs] and private sector), across three countries, and from a wide range of disciplines (such as social science, agricultural economics, agricultural science, nutrition, market analysis and environmental science). While the diversity in disciplines and backgrounds brings obvious advantages when tackling a complex problem with such broad scope, it also brings the challenges in working together mentioned earlier - i.e. differences in theories, methods, language, interests, values and perspectives.

The first phase of the integrated assessment modelling process has involved the development of conceptual models of the socio-ecological systems under investigation with the project partners. The development of such diagrams is a useful way to capture and share understanding (to-date) of the workings of the system - including the key issues and variables, their drivers and their connections with one another. The conceptual modelling is intended to underpin the integrated modelling activities of the team, by encapsulating and structuring the social and environmental context and the problem situation in the case studies. This provides a process to identify the similarities and differences between the study villages. It also provides a process to help the team identify potential linkages between the various research activities.

The initial design for the conceptual models was formulated in the context of risks to the case study communities. Unsurprisingly different team members had divergent views and preferred methodologies and terminologies for similar concepts. During a team workshop, different ideas emerged about how "risk" is defined and how it is assessed. We discussed various existing frameworks - for example, the classical risk formula (risk = likelihood $\mathrm{x}$ impact) and the 'vulnerability framework' commonly used in climate change risk assessment, among others. However none of the existing risk frameworks or conceptual frameworks were deemed appropriate for the scope of issues and impacts addressed in the SIAGI project and how we intended to analyse them (see section 3.1 for further discussion). Furthermore, the existing frameworks posed a significant challenge with the use of terminology (e.g. risk, resilience) that held different meanings to different members of the team. To overcome these challenges, we developed our own framework, which we devised to enable all perspectives and processes (including issues/problems, risks/opportunities) to be mapped out using a common 'language' (presented in section 3.2). The framework was also designed with the view of its potential use for engaging communities. This paper describes the conceptual framework template and the first iteration of conceptual models built by the team.

\section{CONCEPTUALISATION TEMPLATE}

\subsection{Existing approaches}

In the initial stage of the conceptual modelling, a literature review was conducted to find a suitable framework to structure the information about the study systems and its key processes. A range of common frameworks were screened for their suitability, including risk assessment frameworks, the sustainable livelihoods approach (SLA), and the Driver-Pressure-State-Impact-Response (DPSIR) framework.

Our consideration of these frameworks quickly identified challenges of definitions associated with 'risk'. The term 'risk' is frequently used interchangeably to mean several concepts, including: risk as a product of likelihood and impact; risk as in the likelihood or probability of something occurring; risk as in the hazard or source of harm itself (e.g. climate change risk, flood risk); and risk as in the intersection of assets, threats and vulnerabilities (Brooks 2003). Regardless of the risk framework, it became clear that the differences in language will cause difficulties in communication, which we sought to avoid, especially in the initial conceptualisation phase. Furthermore, the nomenclature for risk assessment (e.g. risk, vulnerability, susceptibility, sensitivity and threat etc.) tend to be value-laden concepts. Through discussions, the team agreed that adopting a risk-based conceptual template would more likely lead to the study system being framed negatively, which may present hurdles in identifying opportunities for positive change in the communities.

The sustainable livelihoods approach (SLA) was developed to improve understanding of the livelihoods of the poor, and is widely used in development research. Livelihood assets, central to the framework, affect the ability 
of people to pursue various livelihood strategies (e.g. agricultural intensification, livelihood diversification, migration) (Scoones 1998). Livelihood assets are usually divided into five categories: natural capital (e.g. land, water), human capital (e.g. skills, knowledge), social capital (e.g. social networks), physical capital (e.g. housing, transport) and financial capital (e.g. income, savings, access to credit). These are placed within the external environment referred to as the vulnerability context, which includes trends (e.g. economic trends, changes in politics), shocks (e.g. conflict, death in family, weather) and seasonality (e.g. changing prices, production cycles), which can all impact on people's livelihoods. Under the SLA framework, a livelihood is considered sustainable if it is able to cope with stresses, respond to adverse changes, and maintain or improve its capabilities and assets under all five capitals (Scoones 1998). Some of the limitations of the framework include its focus on livelihoods while ignoring other dimensions of people's lives and well-being; its attempt to consolidate too many social factors into a small number of categories; and its complexity and alienating language (Smyth and Vanclay 2017). While the framework may be useful for identifying key aspects of livelihoods to further investigate, it is considered unsuitable for capturing specific connections or processes between these elements.

DPSIR (Driver-Pressure-State-Impact-Response) is a widely used framework for describing appropriate policy responses to address impacts of human activities on the environment (Eurostat, 1999). Interactions are described as a casual chain starting from the driving force (e.g. human activity, economic sector), to the pressure (e.g. excessive resource use, waste), to the state or condition of an environmental resource (physical, chemical, biological), then its impact on the environment (ecosystem, human health) and the political response (e.g. policy measures, target setting, market signals). There is often confusion amongst the category terms used in the framework (e.g. driver $v s$ pressure, state $v s$ impact) resulting in its misapplication and misunderstandings among scientists, policy-makers and other stakeholders (Oesterwind et al. 2016). The DPSIR framework also has conceptual limitations with its rather rigid template restricting the types of problems that it can describe. For example, the standard framework cannot cope with impacts driven by natural events or forces, or with even moderately complex problems (e.g. an activity that results in multiple pressures, or multiple activities that result in a similar impact) (Patricio et al. 2016). DPSIR also cannot capture social interactions and dynamics, with all socioeconomic processes lumped into 'the social system', which is treated as an external factor (Binder et al. 2013). Given the complexity of problems in the SIAGI project and the centrality of the social component, the DPSIR framework was considered inappropriate.

The SIAGI project required a conceptual framework that was able to: capture a diverse scope of issues and processes (social, biophysical, economics etc) at multiple scales (household, community, regional); describe some level of processes and dynamics to communicate interactions between elements of the system; and be co-developed and understood by a large range of people from various disciplines and backgrounds, without imposing certain values or discipline-specific interpretations. None of the above frameworks were considered adequate for the conceptualizing the socioecological systems investigated by the SIAGI project. We therefore developed a framework that was clear and flexible enough for our needs and would allow us to scale up or down (as needed) in terms of detail and complexity.

\subsection{Our conceptual framework template}

In our conceptual framework template, processes are described in terms of a change to resources, the direct and indirect drivers of this change, and the direct and indirect impacts of the change. The categories and their links remain generic in nature and are neither spatially nor temporally explicit. This enables the template to work with multiple types of processes simultaneously as required. A change in resources can include any increase or decrease in tangible and intangible assets, capabilities, capacities, or behaviours. Additional factors are any factor that increases or reduces either the magnitude of change or impact, or the capacity of the subject to avoid, cope with or adapt to the specified change.

We selected terms that are unambiguous, yet broadly applicable and neutral, avoiding value-judgments. For example, terms such as threat, risk and vulnerability have negative connotations. The use of more neutral terms will enable the framework to also be used to represent opportunities and more positive directions of change. It will also help avoid imposing certain perceptions onto others - for example, what is viewed as a risk or disbenefit by some may be viewed as an opportunity or benefit by others. Therefore the neutral language should be more amenable to cross-cultural contexts and teams. Various knowledge elicitation processes can be used to identify the changes in resources, and their direct and indirect drivers and impacts. In the application described in this paper, a questionnaire distributed via email to project team members was used to collect information to populate the template (see section 4). Face-to-face discussions between the community and project team will occur throughout the remainder of the project to refine and expound the diagrams. 
Figure 2 shows an example of the use of the template. In this example, the change in resource is groundwater depletion, which is caused by decreasing rainfall and over-extraction of groundwater. The over-extraction of groundwater is driven by the lack of enforcement of groundwater policies and the lack of awareness about water conservation in the community. The impacts of the groundwater depletion include reduced volumes of water available for irrigation and poor agricultural productivity. Poor agricultural productivity and/or low market price for produce can lead to financial stress on the household, which in turn can lead to indirect impacts such as seasonal migration, the inability to meet education costs and food insecurity.

The template is modular in nature, so that diagrams can be readily combined to capture multiple system processes and complex pathways of influence. As multiple diagrams are combined, impacts from a change in one resource may become drivers for change in other resources. The template allows divergent ideas from the team to be mapped out and linked together in one common framework, facilitating a genuinely transdisciplinary process.

\section{APPLICATION OF TEMPLATE}

A questionnaire was prepared and sent to the Indian and Bangladesh SIAGI partner organisations, about six months into the project. The conceptual framework template was designed in parallel with our analysis of the questionnaire responses, and some amendments were made to the template after this first application. In the questionnaire, the respondents were asked to identify up to five key issues affecting the rural communities they work with. Recognising that not all partners had yet spent much time with our target communities, they could select any community (as relevant to the SIAGI project as possible) of which they had good understanding. They were asked to describe the issues in terms of who it affects and how, the flow-on effects and their drivers, and to list factors that can improve the capacity of households to avoid, adapt to or cope with the negative impacts of the issues. These questions were aimed at supporting the development of a conceptual diagram that represented what each group considered to be the most important issues to the communities, their drivers and impacts. Conceptual diagrams were created to describe each key issue, in terms of their cause(s) and effect(s). These were then merged to give an overall diagram representing the multiple and diverse range of issues important to each of the communities (Figures 3). Subsequently, 'issues' were reframed as 'change in resources' in the template (Section 3.2) to allow both negative and positive changes in the communities to be represented in the diagrams.

In India, SIAGI has partnered with two research institutes and two NGOs. The two partners (one research institute and one NGO) that had engaged directly with the study villages identified similar issues for the two communities including groundwater depletion, unstable market prices, agrarian stress among women, poor soil health, climate change and poor physical infrastructure (Figure 3). The two partners with limited local experience (at that point in time) identified high level issues relevant to rural communities across India, including position of women, access to capitals, culture and values, resource management, extent of exposure and outside influence, migration, and the relationship between people or communities and institutions.

SIAGI has partnered with one research institute and one NGO in Bangladesh. The key issues identified for marginal or agriculture-dependent communities in Dacope Upazila, one of the study areas in southern Bangladesh, included access to fresh water for irrigation and drinking, saline water and soils, limited access to land for cultivation, limited income generating activities, climatic hazards (e.g. storm surge, cyclones), inequitable value chains and limited access to market, and unequal resource distribution. University colleagues were asked to form two groups and answer the survey separately, one from a livelihoods perspective and the other using a value chains angle (Table 1). The NGO team undertook the exercise as one group. Many issues and variables in common were identified in the three surveys although there were different linkages, ranking of the importance of issues experienced by the community, and the number and detail of variables. An example is provided in Table 1 for issues around the lack of fresh water for irrigation or household consumption. This 
example demonstrates the potential for variation in how individuals and groups may perceive the system, due in part to different problem focus or framing (as requested from university partner) but also reflecting people's expertise and work or personal experiences. At this stage we were not concerned about reconciling these differences. Rather, the purpose was to introduce project partners to conceptual models, and to capture early understanding of the agriculture and livelihood related issues faced by rural communities in our study villages.

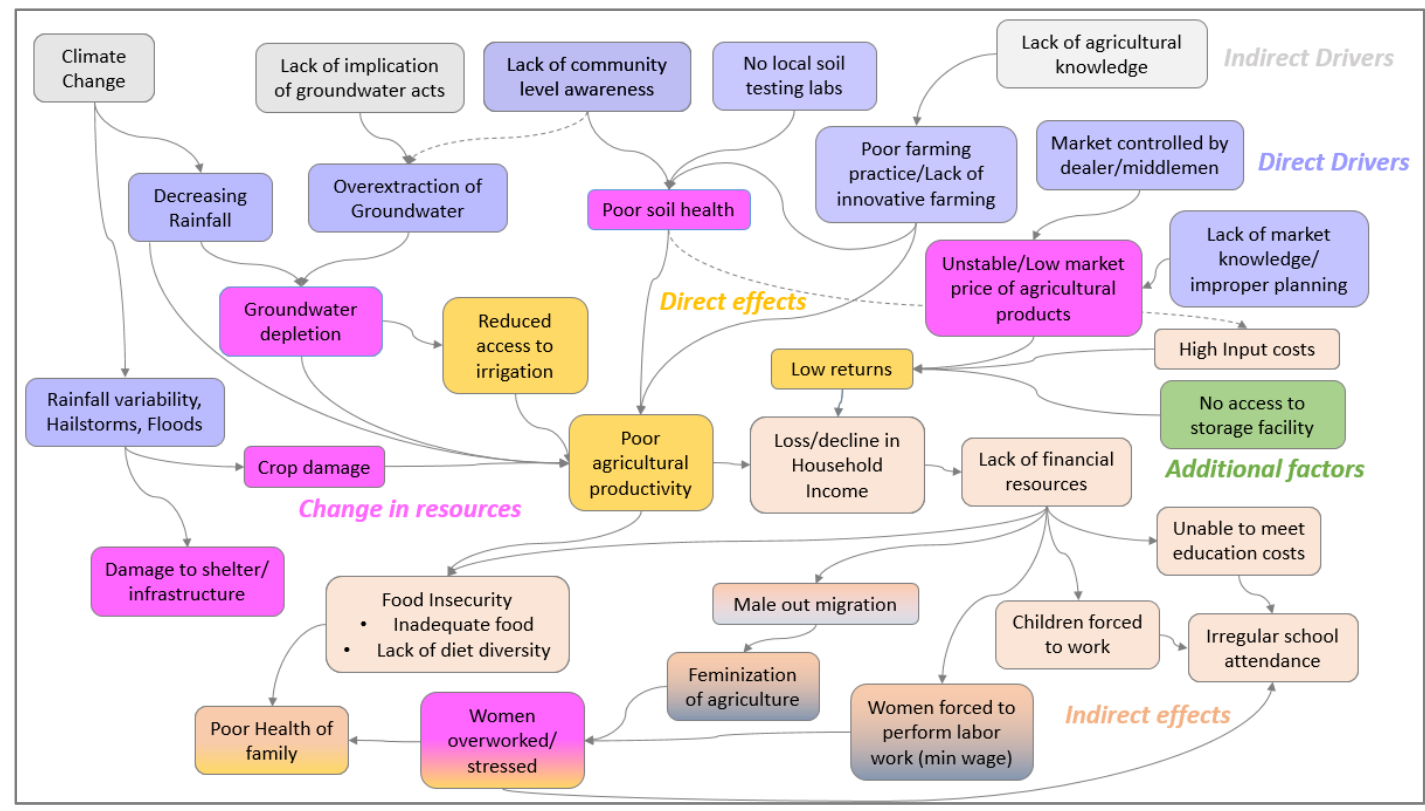

Figure 3. First iteration of the conceptual diagram showing the key issues relevant to the study areas in India, their drivers and effects.

Table 1. The drivers and impacts of changes to fresh water availability in Dacope Upazila, in Bangladesh*.

\begin{tabular}{|c|c|}
\hline Purpose & Variables \\
\hline $\begin{array}{l}\text { Direct or Indirect } \\
\text { driver }\end{array}$ & $\begin{array}{l}\text { Freshwater reservoirs [1,4], Tube wells [1,2], Rainwater harvesting [1,2], Water purification effectiveness [1], } \\
\text { Water treatment plant [2], Salinity intrusion [3], Canal infrastructure (mis-management) [3], Governance } \\
\text { failings \& misuse of power [3], Build new canals / dredge existing canals [4], Tides in Rabi season [4], } \\
\text { Flooding of agricultural land with saline water [4], Drinking water availability [1,2], Water treated to safe } \\
\text { levels for drinking [1,2], Groundwater salinity [3], Soil salinity [3], River salinity [3], Channel siltation [3], } \\
\text { Elite capture of canals [3] }\end{array}$ \\
\hline $\begin{array}{l}\text { Change in } \\
\text { resource }\end{array}$ & $\begin{array}{l}\text { Access to safe drinking water [1,2], Freshwater availability [3], Irrigation water storage [4], Salinity of } \\
\text { irrigation water [4] }\end{array}$ \\
\hline $\begin{array}{l}\text { Direct or indirect } \\
\text { impact }\end{array}$ & $\begin{array}{l}\text { Diarrhoeal water-borne diseases [1], Health impacts [2,3], Drinking water for human and livestock [3], Crop } \\
\text { production [3], Food insecurity [3], Income [4], Dietary diversity [4], Cropping intensity (Rabi) [4] }\end{array}$ \\
\hline Additional factors & $\begin{array}{l}\text { Awareness around drinking water and health [2], Rainwater harvesting [3], Community monitoring and } \\
\text { management [4], Household within canal catchment area? [4] }\end{array}$ \\
\hline
\end{tabular}

\section{DISCUSSION AND CONCLUSION}

This paper described a conceptual framework template designed to allow our project team to articulate key issues faced by rural communities that need to be addressed if socially inclusive and sustainable agricultural intensification is to be achieved.

Individuals within our team have varying disciplinary backgrounds, experiences and worldviews, and (generally) limited exposure to conceptualisation and integrated modelling methodologies. In order to develop conceptual models of the socioecological systems, we required an intuitive framework able to represent multiscale interconnections between the physical and human elements of the system. The framework provided us the flexibility to explore issues either at a high-level, indicative of issues that are common to many rural communities, or for specific communities with their local environmental, political and community context. The questionnaire, designed to elicit drivers and impacts of change for up to five important issues, facilitated the rapid development of issue-specific component diagrams, which could then be compiled by the integrated 
modeller into one diagram. On the whole, the conceptual models developed from this process were negatively framed (e.g. lack of market knowledge, lack of dietary diversity), a critique we had with respect to risk-based conceptual templates. This is due in part to the wording of the questionnaire where we asked our colleagues to identify social, political, market, climate and/or environmental issues facing the communities. However, it is a straightforward process to convert to more neutral framing that can represent opportunities as well as current constraints facing agriculture-dependent communities.

These first iterations of conceptual diagrams represent the SIAGI partners' understanding at the time of the exercise. Further work on the conceptual diagrams will involve the communities to better capture local perceptions of problems and preferred solutions, and will refine the diagrams based on the teams' improved understanding of the communities and relevant system processes. Without direct involvement of community members, attempts to understand and describe the community would simply be conjecture. Engagement is considered essential for capturing the key elements of the interlinked social, economic, environmental and political processes needed for us (jointly with the community) to identify effective options for sustainable agricultural intensification that are coveted by the community and tailored to their needs. It is also crucial in forging a path forward for greater social inclusion and impact in research for development.

\section{ACKNOWLEDGMENTS}

This project (LWR/2014/072) is funded by the Australian Centre for International Agricultural Research (ACIAR). The authors acknowledge contributions from all members of the SIAGI project team.

\section{REFERENCES}

Argent, R.M., Sojda, R.S., Guipponi, C., McIntosh, B., Voinov, A.A., Maier, H.R. (2016). Best practices for conceptual modelling in environmental planning and management. Environmental Modelling and Software 80, 113-121.

Bark, R.H., Kragt, M.E., Robson, B.J. (2016). Evaluating an interdisciplinary research project: Lessons learned for organisations, researchers and funders. International Journal of Project Management 34, 1449-1459.

Binder, CR., Hinkel, J., Bots, P.W.G., Pahl-Wostl, C. (2013). Comparison of frameworks for analyzing socialecological systems. Ecology and Society 18(4): 26.

Brooks, N. (2003). Vulnerability, risk and adaptation: A conceptual framework. Tyndall Centre for Climate Change Research. Working Paper 38.

Eurostat (1999). Towards Environmental Pressure Indicators for the EU, $1^{\text {st }}$ edition. Panorama of the European Union, Theme 8, Environment and Energy. Office for Official Publications of the European Communities, Luxembourg.

Hamilton, S.H., Guillaume, J., ElSawah, S., Jakeman, A.J., Pierce, S.A. (2015). Integrated assessment and modelling: overview and synthesis of salient dimensions. Environmental Modelling and Software 64, $215-$ 229.

Kelly, R.A., Jakeman, A.J., Barreteau, O., Borsuk, M.E., ElSawah, S., Hamilton, S.H., Henriksen, H.J., Kuikka, S., Maier, H.R., Rizzoli, A.E., van Delden, H., Voinov, A.A. (2013). Selecting among five common modelling approaches for integrated environmental assessment and management. Environmental Modelling and Software 47, 159-181.

Klein, J. (2008). Evaluation of interdisciplinary and transdisciplinary research: a literature review. American Journal of Preventive Medicine 35 (2S), S116-S123.

Oesterwind, D., Rau, A., Zaiko, A. (2016). Drivers and pressures - untangling the terms commonly used in marine science and policy. Journal of Environmental Management 181, 8-15.

Patricio, J., Elliott, M., Mazik, K., Papadopoulou, K.-N., Smith, C.J. (2016). DPSIR - Two decades of trying to develop a unifying framework for marine environmental management? Frontiers in Marine Science 3, Art. 177.

Scoones, I. (1998). Sustainable rural livelihoods: a framework for analysis, IDS working paper 72. Institute of Development Studies, University of Sussex, Brighton, UK.

Smyth, E. Vanclay, F. (2017). The Social Framework for Projects: a conceptual but practical model to assist in assessing, planning and managing the social impacts of projects. Impact Assessment and Project Appraisal 35, 65-80.

Tress, G., Tress, B. Fry, G. (2007). Analysis of the barriers to integration in landscape research projects. Land Use Policy 24 (2), 374-385. 